DOI 10.37882/2223-2966.2020.10.26

\title{
ОПТИМИЗАЦИЯ ЛЕЧЕНИЯ ПАЦИЕНТОВ С СИНДРОМОМ ДИАБЕТИЧЕСКОЙ СТОПЫ
}

\section{OPTIMIZATION OF TREATMENT OF PATIENTS WITH DIABETIC FOOT SYNDROME}

\section{A. Sakharyuk \\ N. Semenov \\ E. Nuriyev \\ A. Tarasov}

Summary: One of the most important non-communicable diseases (NCDS) is diabetes mellitus. The higher the number of patients with diabetes, the higher the number of concomitant diseases of the chronic type increases. The main complication in patients with diabetes is diabetic foot syndrome. This complication is an acute social as well as medical problem. Despite modern medical technologies in the field of endocrinology, statistics show an increase in the number of surgical operations to remove the foot. The nature of these statistics is not optimistic. Today, more than $60 \%$ of surgical amputations of the lower extremities are performed in patients with diabetes mellitus [1, 2]. the Effectiveness of such treatment is about $30 \%[3,4]$. In the treatment of diabetic foot syndrome, there are many tasks that remain unresolved. Currently, there is a formation and development of newer and quite effective methods of treatment of this syndrome. One such promising method may be the method of combined intravenous laser irradiation of blood with a «blue» laser (the wavelength of which is $450 \mathrm{~nm}$ ), as well as blood ozonation in patients with diabetic foot syndrome. This study confirms the effectiveness of its use.

Keywords: diabetic foot, blood ozonation, blood irradiation, surgical treatment.

\author{
Сахарюк Александр Петрович \\ Ә.м.н., профессор, Амурская ГМА \\ Семенов Николай Владимирович \\ Городская больница им. Ф.С. Анкудинова, \\ г. Южно-Сахалинск
}

Нуриев Эльнур Самедович аспирант, Амурская ГМА; врач-хирург, городская больница им. Ф.С. Анкудинова elvir300@yandex.ru

Тарасов Андрей Николаевич анестезиолог-реаниматолог, Городская больница им. Ф.С. Анкудинова г. Южно-Сахалинск

Аннотация: Одним из важных неинфекционных заболеваний (НИЗ) является именно сахарный диабет. Основным осложнением у больных сахарным диабетом, является синдром диабетической стопы. Данное осложнение представляет собой острую общественную, а также медицинскую проблему. Несмотря на современные медицинские методы лечения в области эндокринологии, статистика говорит 06 увеличении числа хирургических операций по удалению стопы. На сегодняшний день более $60 \%$ хирургических ампутаций нижних конечностей проводятся у больных сахарным диабетом $[1,2]$. Результативность такого лечения составляет около 30\% [3, 4]. В лечении синдрома диабетической стопы остается множество задач, которые являются нерешенные. В настоящее время происходит формирование и развитие более новых и достаточно результативных методов лечения указанного синдрома. Одним таким перспективным способов, может стать метод комбинированного внутривенного лазерного облучения крови лазером «синего» цвета (длина волны 450 нм), а также озонирование крови у больных синдромом диабетической стопы. Настоящее исследование приводит подтверждение результативности его использования.

Ключевые слова: диабетическая стопа, озонирование крови, облучение крови, хирургическое лечение.

выше проблема, является основанием для проведения данного исследования.

В настоящей статье рассматривается метод использования комбинированного внутривенного лазерного облучения крови лазером «синего» цвета (длина волны 450 нм) а также озонирование крови у больных синдромом диабетической стопы в комплексном лечении.

\section{Шель исслеАований}

Проанализировать и выполнить оценку результативности использования способа комбинированного внутривенного лазерного облучения крови «синим» лазером и озонированием крови у больных с синдромом диабетической стопы. 


\section{Материалы и методы}

В рамках настоящего исследования был проведен анализ результатов лечения больных в количестве 80 человек. У обследуемых наблюдалось наличие гнойнонекротических форм синдрома диабетической стопы. Настоящее исследование проводилось в период с 1 февраля 2019 года по 1 марта 2020 года. Исследование было проведено на базе второго хирургического отделения городской больницы им. Ф.С. Анкудинова, города Южно-Сахалинск. Из 80 обследуемых 68,75\%, а именно 55 женщины, а остальные 31,25\%, а именно 25 - мужчины. Примерный возраст обследуемых составляет 53 года, отклонение - $\pm 1,5$ лет. Все обследуемые имеют заболевание - сахарный диабет второго типа. 57 человек из 80 (71.25\%) больны сахарным диабетом легкой степени тяжести. Уровень глюкозы в крови не превышает 8.5 ммоль/л, а в моче около 24 грамм. 23 человека из 80 больных сахарным диабетом средней степени тяжести, другими словами, уровень сахара в крови достигал значений до 14 ммоль/л, а в моче не превышал 40 граммов. У данной группы с небольшой периодичностью в моче обнаруживались следы ацетона. Согласно сведениям Уздг у 70 обследуемых (87,5\%) наблюдалось сохранение магистрального тока крови, по всей пораженной конечности. У 10 человек (12,5\%) были обнаружены поражение кровеносных сосудов тибиально-стопного сегмента). Сведения о присутствии у пациентов критической ишемии отсутствуют. Все обследуемые были разбиты на две группы по глубине распространения гнойно-некротического процесса: 3 степени - 62 человека, и 4 степени - 18 человек (77,5\% и 22,5\% соответственно). 60 человек (75\%) - нейропатический тип синдрома диабетической стопы, а остальные 20 человек (25\%) - нейроишемическим типом. Клиническая картина была представлена следующими формами: пациенты с сухой гангреной стопы составили 10 (14,8\%), трофическими язвами -14 (18,5\%), гнойно-некротическими ранами стопы - 35(29,6\%), флегмонами стопы - 21 (37\%). Язвенные повреждения стоп у основной группы имели размеры около 39,8-41,2 см2, а у контрольной группы 41- 42,6 см2. Эти сведения определены тем, что большинство больных обратились в медицинское учреждение на достаточно позднем периоде течения болезни. При лечении пациентов необходимо было обращать внимание на ряд сопутствующих патологий. Это необходимо по той причине, что сопутствующие заболевания негативно влияют на течение основной патологии. у 44 (55\%) была обнаружена гипертоническая болезнь, у 16 (20\%) - ишемическая болезнь сердца. Алиментарное ожирение у 10 (12,5\%) пациентов, постинфарктный кардиосклероз - у 10 (12,5\%) обследуемых.

Терапию проводили с помощью «синего» лазера внутривенным облучением крови аппаратом «Солярис ВЛОК» одноканальный с непрерывным излучением, длина волны которого составляет 450 нм средняя мощность излучения на выходе одноразового световода не менее 1 мВт, совместно в озонированным физиологическим раствором с концентрацией озона 2 мкг/мл (200 мл в сутки) струйным введением в диапазоне 5 минут, в темном помещении. Озонирование физиологического раствора проводилось с помощью аппарата «Медозон 01». Курс лечения составил - 10 дней (10 процедур), продолжительность одного сеанса 15-20 минут. В ходе лечения концентрация озона в физ.растворе составляла 2мкг\мл. Данное значение является наиболее оптимальной, т.к. увеличение концентрации озона в физ.растворе может привести к возникновению осложнений у пациентов, таких как флебит.

Критерии исключения, следующие:

- активные курильщики;

- пациенты, которые перенесли осложнения атеросклероза (менее полугода);

- пациенты, обладающие любыми заболеваниями воспалительного характера, в стадии обострения;

- ХБП $\geq$ III стадий - скорость клубочковой фильтрации (СКФ) <60 мл/мин/1,73 м2;

- фракция выброса левого желудочка <40\%;

- больные онкологией, заболеваниями кроветворной и иммунной систем.

Обработка полученных в ходе исследования сведений, проводилась опираясь на рекомендации Ребровой O.Ю. (2002), применялась при этом программа STATISTICA 10. Применяли $5 \%(p=0,05)$ доверительный интервал. Полученные материалы рассматривали как непараметрические. Ввиду этого проверку нормальности распределения количественных признаков не выполняли. С целью оценки распределения непрерывных величин в связанных группах использовали критерий Манн-Уитни.

Нозологические формы сопутствующих заболеваний у пациентов с сдс.

\begin{tabular}{|l|c|c|}
\hline $\begin{array}{c}\text { Нозологическая форма } \\
\text { сопутствующего } \\
\text { заболевания }\end{array}$ & $\begin{array}{c}\text { Абсолютное количество } \\
\text { пациентов }\end{array}$ & $\begin{array}{c}\text { \% количество } \\
\text { пациентов }\end{array}$ \\
\hline $\begin{array}{l}\text { Гипертоническая болезнь } \\
\text { Ишемическая болезнь } \\
\text { сердца }\end{array}$ & 44 & 55 \\
\hline Ожирение 2-3 степени & 16 & 20 \\
\hline $\begin{array}{l}\text { Постинфарктный } \\
\text { кардиосклероз }\end{array}$ & 10 & 12,5 \\
\hline
\end{tabular}


Клинические формы гнойно-деструктивных заболеваний у пациентов с сдс.

\begin{tabular}{|l|c|c|}
\hline $\begin{array}{c}\text { Клинические формы } \\
\text { гнойно-деструктивных } \\
\text { поражений конечности }\end{array}$ & $\begin{array}{c}\text { Абсолютное число } \\
\text { пациентов }\end{array}$ & $\begin{array}{c}\text { \% категории } \\
\text { пациентов }\end{array}$ \\
\hline $\begin{array}{l}\text { сухой гангреной стопы } \\
\text { составили }\end{array}$ & 10 & $14,8 \%$ \\
\hline $\begin{array}{l}\text { гнойно-некротическими } \\
\text { ранами стопы }\end{array}$ & 35 & $29,6 \%$ \\
\hline трофическими язвами & 14 & $18,5 \%$ \\
\hline флегмонами стопы & 21 & $37 \%$ \\
\hline
\end{tabular}

Пациенты были сопоставимы по локализации гнойного процесса, полу, возрасту, наличии сопутствующих заболеваний. Лечение было комплексным. Схема лечения включала в себя:

- хирургическое лечение (проведение малых ампутации и некрэктомии)

- терапевтическое лечение, (необходимость компенсации углеводного обмена, согласно рекомендациям эндокринолога);

- антибактериальную терапию

- дезинтоксикационную терапию (при необходимости);

- метаболическую терапию;

- антиагрегантную терапию;

- -местное лечение, которое включало перевязки с антисептическими растворами, с ферментативными покрытиями, гидрофильными мазями и препаратами на основе гиалуроновой кислоты.

В зависимости от того, какая нужна была тактика лечения пациентов разделили на две группы. Группа 1 является основной была представлена 55 (68,75\%) пациентами- кроме традиционной терапии они получали лечение методом комбинированного лазерного облучения крови «синим лазером» 450нм и озонирование крови по ранее разработанной нами схемой. Пациенты группы 2 (контрольная группа) 45 (31,25\%) получали лечение по традиционной схеме. Результатами проведенной работы стало: у пациентов второй группы к 16 суткам отмечали слабую положительную динамику, а именно: болевой синдром был купирован лишь у 15 (33,3\%), отечность стопы уменьшилась только у 10 (22,2\%) пациентов. В первой группе, где в комплексе с традиционной терапией проводили лечение согласно разработанной методике, результатом было снижение болей в стопах и явлений парастезий на 5-7 сутки. гиперемии окружающих тканей снизилась на 2 сутки, уменьшился отек местно на 3-4 сутки, инфильтрация краев ран на 3 сутки. Анализ данных важных показателей течения раневого процесса показал, что в контрольной группе средние сроки очищения ран составили $14,3 \pm 0,9$ суток, появление грануляционной ткани заме-

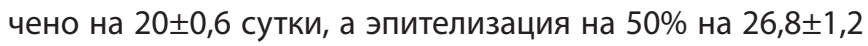
сутки. Во второй группе, где проводили комплексное лечение совместно с разработанной методикой ВЛОК + озо- нирование крови средние сроки очищения ран от детализированных тканей составили 6,3 0,4 сутки, появление

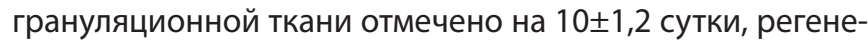

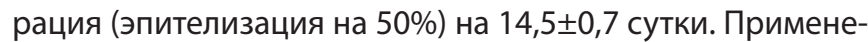
ние методики в комплексном лечении трофических язв и длительно незаживающих ран у пациентов с СДС дала положительную динамику в виде сокращения времени очищения раневых дефектов приблизительно в 2,2 раза, появления грануляций и регенерации (эпителизация на 50\%) в 2 раза. В основной группе площадь гнойных ран сократилась к третьей неделе на 65\% и составило 14,2 \pm 1,5 cм2, а при традиционном лечении у пациентов контрольной группы площадь гнойных ран уменьшилась на $28,3 \%$ и составило $30 \pm 1,4$ см2

Показатели течения раневого процесса у обеих групп

\begin{tabular}{|l|c|c|c|}
\hline \multirow{2}{*}{ Группы больных } & $\begin{array}{c}\text { Очищение } \\
\text { раневой } \\
\text { поверхности }\end{array}$ & \multicolumn{1}{|c|}{$\begin{array}{c}\text { Появление } \\
\text { грануляции }\end{array}$} & $\begin{array}{c}\text { Заживление } \\
\text { (эпитализация } \\
\text { на 50\%) }\end{array}$ \\
\cline { 2 - 4 } & \multicolumn{3}{|c|}{ Средние сроки в (сутках) } \\
\hline 1 группа $n=55$ & $6,0 \pm 0,4^{*}$ & $10 \pm 1,2^{*}$ & $15,5 \pm 0,7^{*}$ \\
\hline $\begin{array}{l}2 \text { группа } \\
\text { контрольная } \\
n=45\end{array}$ & $14,3 \pm 0,9$ & $20 \pm 0,6$ & $26,8 \pm 1,2$ \\
\hline
\end{tabular}

Примечание: * - достоверность отличия от показателей 2 группы $(p<0,01)$.

Изменения площади ран у пациентов

\begin{tabular}{|l|c|c|c|c|}
\hline \multirow{2}{*}{ Группы больных } & \multicolumn{4}{|c|}{ Площадь ран (см2) } \\
\cline { 2 - 5 } & $\begin{array}{c}\text { До лече- } \\
\text { ния }\end{array}$ & $\begin{array}{c}\text { После 7 } \\
\text { суток }\end{array}$ & $\begin{array}{c}\text { После } 14 \\
\text { суток }\end{array}$ & $\begin{array}{c}\text { После 21 } \\
\text { суток }\end{array}$ \\
\hline 1 группа $\mathrm{n}=55$ & $40,5 \pm 0,7$ & $34,5 \pm 1,5$ & $23,7 \pm 1,6^{*}$ & $14,2 \pm 1,5^{*}$ \\
\hline $\begin{array}{l}\text { 2группа } \\
\text { (контрольная) } \\
\mathrm{n=45}\end{array}$ & $41,8 \pm 0,8$ & $38,5 \pm 1,3$ & $35,4 \pm 1,5$ & $30 \pm 1,4$ \\
\hline
\end{tabular}

Примечание: * - достоверность отличия от показателей 2 группы $(p<0,01)$.

\section{Выво $\Delta$ ы:}

Полученные данные показали, что использование в комплексном лечении метода ВЛОК + озонирование крови благоприятно воздействует на скорость очищения поверхности раны от гнойно-некротического детрита. По сравнению с традиционным лечением снижено время создания и роста грануляции и эпителизации раны.

Разработанная нами методика комплексного лечения пациентов с синдромом диабетической стопы, основанная на применении комбинированного внутривенного лазерного облучения (450 нм) и озонировании крови, судя по полученным данным по эффективности в лечении превосходит традиционную методику и может быть использована в широкой клинической практике. 


\section{ЛИТЕРАТУРА}

1. Анциферов, М.Б. Книга для пациентов с сахарным диабетом 2 типа / М.Б. Анциферов. - Москва: Мир, 2017. Стр. 196

2. Дедов И.И., Краснопольский В.И., Сухих Г.Т. и др. Российский национальный консенсус «Гестационный сахарный диабет; Диагностика, лечение, послеродовое наблюдение» // Сах.диаб. -2019. - № 4. - Стр. 4-10.

3. Russell, Jessie Vitamins in diabetes mellitus / Jessie Russell. - London.: VSD, 2017. - cтp. 549.

4. Russell, Jessie Changes in organs and systems in diabetes mellitus / Jessie Russell, London:VSD, 2018, стр. 267.

5. Азизов Г.А., Козлов В.И. Внутривенное лазерное облучение крови в комплексном лечении заболеваний сосудов нижних конечностей. Пособие для врачей. / М: НПЛЦ «Техника» 2003; 24.

6. Раджабов А.А., Дербенев В.А., Гусейнов А.И., Исмагилов Г.И., Комплексное лечение длительно незаживающих язв нижних конечностей. // Журнал лазерная медицина 23. S3 -2019- Т3. Стр. 24-25.

7. Шимко В.В., Нуриев Э.С., Бурдиловская О.В., Анализ микроциркляции у больных диабетической стопой. // Журнал лазерная медицина 23. S3- 2019- Т3. Стр. 31.

8. Мараев В.В., Елисеенко В.И., Мусаев М.М., Дуванский В.А., // Журнал лазерная медицина 23. S3 -2019- Т3. Стр. 22.

9. Шимко В.В., Семенов Н.В., Нуриев Э.С., Тарасов А.Н., Борзенко Д.В., Разработка метода комбинированного внутривенного лазерного облучения крови «синим лазером» (450Нм) и озонированием крови у пациентов сахарным диабетом, осложненным диабетической стопой. // Журнал Национальное здоровье Выпуск №1 - 2019г. стр 10-19

( С Сахарюк Александр Петрович, Семенов Николай Владимирович, Нуриев Эльнур Самедович (Ivir300@yandex.ru),

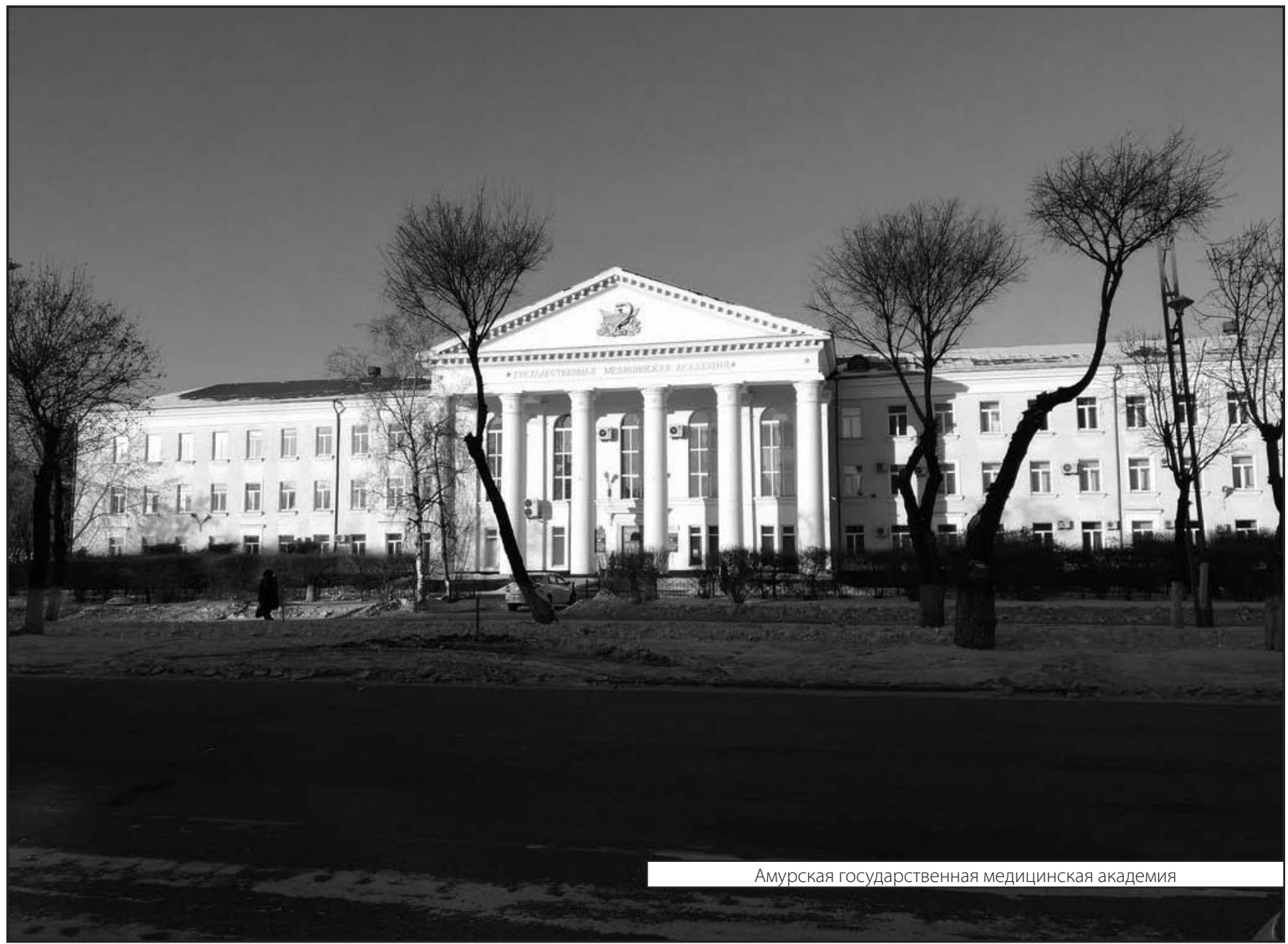

